\title{
IDENTIFIKASI JENIS BERAS MELALUI AKURASI KEMIRIPAN FITUR BENTUK DAN WARNA
}

\author{
Jumi $^{1}$, Utami Tri Sulistyorini ${ }^{2}$, Azizah ${ }^{3}$ \\ 1,3, Jurusan Administrasi Niaga, ${ }^{2}$ Jurusan Akuntansi \\ Politeknik Negeri Semarang \\ ${ }^{1}$ Email: jumimail06@gmail.com, ${ }^{2}$ utamitrisulistyorini@gmail.com, ${ }^{3}$ azzizah01@gmail.com
}

\begin{abstract}
Abstrak - Pengembangan pengetahuan terapan bidang teknologi yang memajukan industri di masyarakat merupakan rencana induk penelitian Perguruan Tinggi yang salah satu bidang fokusnya adalah pengembangan teknologi informasi. Bidang Teknologi informasi dibutuhkan hampir disemua bidang industri, diantaranya adalah industri pangan dengan salah satu komoditinya yaitu beras. Bahwa Beras merupakan salah satu komoditi unggulan pertanian di Indonesia yang memiliki berbagai level kualitas dan jenis. Banyaknya jenis dan level kualitas beras memerlukan database dan identifikasi yang tepat serta konsisten dalam mengklasifikasikannya. Penentuan level kualitas dan jenis beras dapat dilakukan dengan menggunakan data visual yaitu citra beras. Setiap jenis beras memiliki ciri fisik yang relatif berbeda, begitu juga setiap level kualitas beras memliki ciri fisik yang berbeda. Melalui ciri fisik pada citra yaitu bentuk dan warna akan ditemukan level kualitas dan jenis beras.

Ciri atau fitur fisik beras yang tersimpan pada citra sangat dipengaruhi oleh kondisi pada saat pengambilan citra beras seperti pencahayaan, posisi pengambilan dan jarak kamera dengan obyek yang selanjutnya akan berpengaruh terhadap hasil identifikasi. Hal ini memerlukan metode pengolahan citra untuk meningkatkan akurasi deteksi agar identifikasi kualitas dan jenis beras memiliki tingkat validasi yang tinggi.

Pada penelitian ini dikembangkan model identifikasi level kualitas dan jenis beras melalui pengenalan citra beras menggunakan fitur bentuk dan warna. Pengolahan citra meliputi preprocessing, ekstraksi dan klustering. Hasil penelitian menunjukkan bahwa dengan menggunakan kombinasi fitur bentuk dan warna identifikasi kualitas dan jenis beras memiliki akurasi mencapai lebih dari $80 \%$.
\end{abstract}

Kata Kunci: Identifikasi, beras,bentuk, warna, akurasi

\section{PENDAhuluan}

Padi yang selanjutnya diproses menjadi beras merupakan salah satu produk unggulan pangan nasional dan produk unggulan pertanian di Indonesia. Cadangan atau stock beras merupakan salah satu komponen dalam perwujudan kedaulatan pangan yang terdapat pada UU No. 18 Tahun 2012 [1]. Beras hasil pertanian di Indonesia memiliki beragam jenis dan kualitas. Beberapa jenis beras yang paling diminati pasar menurut survey (BPS Nasional, 2008) adalah Beras Pandan Wangi, Rojolele, Memberamo dan $\mathrm{C} 4$, sedangkan beras jenis IR dan jenis lainnya kurang diminati pasar meskipun harganya lebih murah karena kualitasnya kurang bagus. Setiap jenis beras memiliki berbagai kualitas yang dapat di bedakan menurut warna, bau serta ukuran bulirnya. Pada setiap jenis dilakukan pengelompokan beras menurut kualitasnya diantaranya beras dengan bulir utuh, wangi baunya dan bening warnanya dikategorikan beras level paling bagus, sedangkan beras dengan bulir patah-patah ukuran kecil atau disebut menir, bau dan warnanya gelap kropos dikategorikan beras dengan kualitas level paling rendah.

Klasifikasi atau pengelompokan level kualitas dan jenis beras didasarkan pada ukuran bulir (kepala, patah, menir), warna (merah, kuning atau rusak), kondisi bulir ( mengapur, keretakan), warna ( derajat putih dan kebeningan) (SNI 6128:2015). Kriteria-kriteria standard mutu melalui pengecekan manual menghasilkan informasi yang cenderung kurang konsisten karena dipengaruhi oleh situasi dan kondisi manusia. Hasil pengukuran kualitas pada jenis beras yang sama jika diukur secara manual menghasilkan level kualitas atau bahkan jenis beras yang berbeda.

Pengukuran kualitas dan penentuan jenis beras secara manual atau secara kasat mata sulit mendapatkan ukuran yang konsisten bahkan kadang-kadang menghasilkan ukuran kualitas atau jenis beras yang salah. Hal ini memerlukan keahlian khusus mulai dari deteksi kualitas dan jenis beras yaitu dengan menggunakan pengolahan citra melalui ciri phisik yang dimiliki masing-masing jenis beras. Secara umum setiap objek citra memiliki tiga ciri phisik atau fitur yaitu bentuk, warna dan tekstur. Ketiga fitur tersebut mewakili objek realnya yang mampu memberikan informasi level kualitas dan jenis beras.

Beberapa penelitian sebelumnya tentang identifikasi beras telah dilakukan diataranya penelitian tentang evaluasi kualitas beras 
menggunakan bentuk morfologi masing-masing beras [3], kemudian identifikasi tingkat kerusakan beras menggunakan kombiansi operator thresholding dan morfologi untuk mengelompokkan beras menjadi beras rusak, tidak rusak, dibilas dan dirusak [4]. Penelitian tentang seleksi kualitas beras melalui citra beras juga dilakukan oleh [6].

Dalam sistem deteksi dan identifikasi citra beras, pencahayaan dan jarak pengambilan citra merupakan sebuah penelitian tersendiri yang perlu dikembangkan untuk mendapatkan sistem deteksi dan identifikasi dengan menghasilkan ukuran yang mendekati sempurna dan konsisten. Begitu pula penggunaan semua fitur dasar phisik citra yaitu fitur bentuk dan warna juga penting untuk dikombinasi atau digabungkan agar menghasilkan sistem deteksi dan identifikasi dengan akurasi yang tinggi [7].

Sistem identifikasi kualitas dan jenis beras yang dibangun pada penelitian ini merupakan sebuah sistem identifikasi dengan menggunakan camera yang berfungsi sebagai alat deteksi secara realtime. Identifikasi kualitas dan jenis beras menggunakan kombinasi atau gabungan dua fitur citra beras hasil feature extraction dari citra input yang sudah diperbaiki pada tahap preprocessing . kedua fitur tersebut yaitu fitur bentuk (shape) dan warna (color) digunakan sebagai deskriptor untuk menentukan kualitas dan jenis beras agar menghasilkan akurasi lebih dari $80 \%$.

\section{Color Moments dan Invariant Moments}

\subsection{Color Moments}

Warna merupakan hasil persepsi cahaya dalam spektrum wilayah yang terlihat oleh retina mata, dan memiliki panjang gelombang antara 400nm sampai 700nm. Visualisasi dari wang warna RGB merupakan sebuah kubus seperti pada Gambar 2.1, yang mempunyai 3 sumbu untuk mewakili warna $\mathrm{R}$ (red) atau merash, $\mathrm{G}$ (green) atau Hijau dan B (blue) atau biru. Salah satu sudut alasnya yang berlawanan menyatakan warna hitam ketika nilai $\mathrm{R}=\mathrm{G}=\mathrm{B}=0$, sedangkan sudut atasnya yang berlawanan menyatakan warna puti ketika nilai $\mathrm{R}=\mathrm{G}=\mathrm{B}=255$ (sistem warna 8 bit).

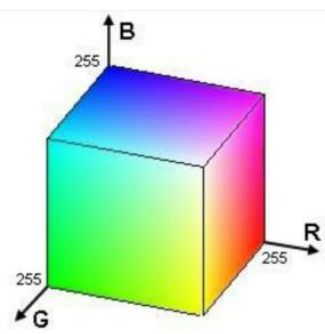

Gambar 2.1 Komponen warna RGB sebagai vektor intensitas warna
Warna disajikan berdasarkan tiga warna dasar, dimana setiap warna dapat direproduksi dengan pencampuran satu set yang sesuai dengan tiga warna dasar. Banyaknya warna tergantung pada tiga vektor komponen warna pada ruang tiga dimensi pada sistem koordinat. Himpunan semua warna membentuk suatu ruang vektor disebut color space atau color model.

Warna dapat digambarkan sebagai suatu penyajian ruang metrik warna sehingga suatu perbedaan warna dapat dihitung menggunakan perbedaan jarak melalui euclidean distance. Persamaan transformasi ditunjukkan oleh persamaan 1 digunakan untuk konversi nilai vektor dari RGB ke bentuk $\mathrm{L}^{*} \mathrm{a} * \mathrm{~b}$, nilai masingmasing $\mathrm{L}^{*}$ pada persamaan 2 , a* pada persamaan 3 , dan $b^{*}$ pada persamaan 4 .

$$
\begin{aligned}
& {\left[\begin{array}{l}
X \\
Y \\
Z
\end{array}\right]=\left[\begin{array}{ccc}
0.490 & 0.310 & 0.200 \\
0.199 & 0.813 & 0.11 \\
0.000 & 0.010 & 0.990
\end{array}\right]} \\
& =\left[\begin{array}{l}
R \\
G \\
B
\end{array}\right] \\
& L^{*}=25\left(\frac{100 y}{y o}\right) \quad 1 / 3 \\
& -16 \\
& a^{*}=500\left[\left(\frac{x}{x o}\right) \quad 1 / 3\right. \\
& \left.-\left(\frac{y}{y o}\right) \quad 1 / 3\right] \\
& b^{*}=200\left[\left(\frac{y}{y o}\right) \quad 1 / 3\right. \\
& \left.-\left(\frac{Z}{Z O}\right) \quad 1 / 3\right]
\end{aligned}
$$

Pada persamaan 2, 3 dan 4 dibatasi untuk $1<=100 Y<=100$ harus dipenuhi, nilai antara (XYZ)T adalah nilai tristimulus dari CIE XYZ dan [X0 Y0 Z0]T adalah referensi warna putih. $\mathrm{L}^{*}$ berhubungan dengan brightness, $\mathrm{a}^{*}$ untuk redgreen dan $b^{*}$ untuk yellow-blue. Bentuk yang sama dapat ditemukan dalam sistem koordinat L*u*v. Model warna HSV (Hue, Saturation, Value) digambarkan pada Gambar 2.2 


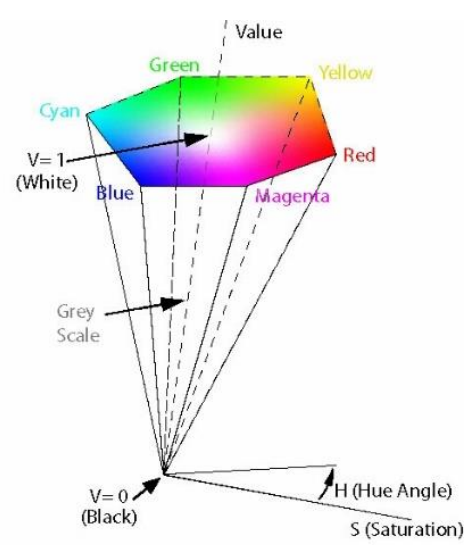

Gambar 2.2 HSV Hexcone color model

Color Moments adalah suatu metode yang digunakan untuk membedakan citra berdasarkan fitur warnanya. Adapun dasar teori dari metode ini adalah dengan mengasumsikan bahwa distribusi warna pada sebuah citra dapat dinyatakan sebagai distribusi probabilitas.Color Moment merupakan metode yang cukup baik dalam pengenalan ciri warna. Metode ini menggunakan tiga moment utama dari distribusi warna citra yaitu mean, standard deviation, dan skewness, sehingga metode ini menghasilkan tiga nilai untuk masing-masing komponen warna [2]. Setiap komponen warna yaitu HSV (Hue, Saturation dan Value) memiliki 3 moment. Penghitungan ketiga moment tersebut menggunakan persamaan 5, persamaan 6 dan persamaan 7 .

a. Moment 1-Mean :

$$
E=\frac{1}{N} \sum_{j-1}^{N} \mathrm{Pij}
$$

Mean : dapat dikatakan sebagai rata-rata nilai warna pada citra.

b. Moment 2 - Standard Deviation :

$$
\sigma_{i}=\sqrt{\left.\left(\frac{1}{N} \sum_{j-1}^{N} P_{i j}-E_{i j}\right)^{2}\right)}
$$

Standard deviation: jangkauan tersebarnya data dari mean

c. Moment 3 -Skewness :

$$
S_{i}=\sqrt[3]{\left(\frac{1}{\mathrm{~N}} \sum_{\mathrm{j}-1}^{\mathrm{N}}\left(\mathrm{P}_{\mathrm{ij}}-\mathrm{E}_{\mathrm{i}}\right)^{3}\right)}
$$

Skewness : ukuran asimetri data disekitar mean, dihitung dengan persamaan (7).

\section{d. Jarak Distribusi Warna}

Jarak dari distribusi warna citra query dengan citra database dihitung dengan persamaan(8).

$$
\begin{aligned}
D_{\text {color }}(H, I)= & \sum_{i=1}^{r} W_{i 1}\left|E_{i}^{1}-E_{i}^{2}\right|+W_{i 2} \mid \sigma_{i}^{1} \\
& -\sigma_{i}^{2}\left|+W_{i 3}\right| S_{i}^{1}-S_{i}^{2} \mid
\end{aligned}
$$

\begin{tabular}{|c|c|c|}
\hline $\mathrm{E}$ & $=$ & Rata-rata nilai warna citra (Mean) \\
\hline$(\mathrm{H}, \mathrm{I})$ & $=$ & Dua citra yang dibandingkan \\
\hline $\mathrm{i}$ & $=$ & $\begin{array}{l}\text { Indeks Komponen warna } \mathrm{HSV}( \\
\mathrm{H}=1, \mathrm{~S}=2, \mathrm{~V}=3)\end{array}$ \\
\hline $\mathrm{r}$ & $=$ & Jumlah Indeks ( 3 ) \\
\hline$\sigma$ & $=$ & $\begin{array}{l}\text { Akar pangkat dari varians } \\
\text { (Standard Deviasi). }\end{array}$ \\
\hline $\mathrm{S}$ & $=$ & $\begin{array}{l}\text { Ukuran derajat asimetri } \\
\text { (Skewness). }\end{array}$ \\
\hline $\mathrm{N}$ & $=$ & Jumlah total piksel pada citra. \\
\hline $\mathrm{J}$ & $=$ & Urutan piksel. \\
\hline $\mathrm{Wi}$ & $=$ & $\begin{array}{l}\text { Bobot (weight) masing-masing } \\
\text { moment. }\end{array}$ \\
\hline Pij & $=$ & $\begin{array}{l}\text { Nilai komponen warna ke-i } \\
\text { pada pixel ke-j }\end{array}$ \\
\hline
\end{tabular}

Wi : bobot (weight) dari setiap momen yang dispesifikasikan oleh user.

\subsection{Invariant Moments}

Formula invariant moments diperkenalkan oleh [8] Formula ini menghasilkan ciri citra berdasarkan bentuk dengan ciri-ciri yang diperoleh dari perubahan citra dengan melakukan Rotation, Scale dan Translation (RST)-invariant [5].

Invariant moment adalah sebuah fungsi yang banyak digunakan dalam teori probabilitas yang diterapkan untuk analisis bentuk himpunan momen suatu fungsi $\mathrm{f}(\mathrm{x}, \mathrm{y})$ dari dua variabel didefinisikan sebagai berikut [8].

Moment order $(\mathrm{p}+\mathrm{q})$ untuk fungsi kontinu $\mathrm{f}(\mathrm{x}, \mathrm{y})$ dengan $\mathrm{p}, \mathrm{q}=0,1,2$, dan seterusnya yang didefinisikan sebagai berikut: 


$$
m_{p q}=\int_{-\infty}^{\infty} \int_{-\infty}^{\infty} x^{p} y^{q} f(x, y) d x d y
$$

Sedangkan Central moment didefinisikan seperti dibawah ini:

$$
\begin{gathered}
\mu_{p q}=\int_{-\infty}^{\infty} \int_{-\infty}^{\infty}(x-\bar{x})^{p}(y-\bar{y})^{q} f(x, y) d x d y \\
\quad \text { dengan } \\
\bar{x}=\frac{m_{10}}{m_{00}} \quad \text { dan } \quad \bar{y}=\frac{m_{01}}{m_{00}}
\end{gathered}
$$

Adapun Untuk citra digital

$$
\mu_{p q}=\sum_{x} \sum_{y}(x-\bar{x})^{p}(y-\bar{y})^{q} f(x, y)
$$

Area diilustrasikan dengan tujuh invariant moment yang dapat dicari dari momen sentral: $\mu 00, \mu 10, \mu 01, \mu 20, \mu 11, \mu 02, \mu 30, \mu 12, \mu 21$, $\mu 03$, dengan mendefisinikan normalized central moments sebagai $\eta p q=\mu p q / \mu \gamma 00$, dimana

$\gamma=0.5(p+q)+1$ untuk $p+q=2,3$, dan selanjutnya menghasilkan tujuh invariant moments, ketujuh invariant moments tersebut adalah:

$$
\begin{aligned}
\varphi 1= & \eta 20+\eta 02 \\
\varphi 2= & (\eta 20-\eta 02) 2+4 \eta 211 \\
\varphi 3= & (\eta 30-\eta 12) 2+(3 \eta 21-\eta 03) 2 \\
\varphi 4= & (\eta 30+\eta 12) 2+(\eta 21+\eta 03) 2 \\
\varphi 5= & (\eta 30-3 \eta 12)(\eta 30-\eta 12)[(\eta 30+\eta 12) 2- \\
& 3(\eta 21+\eta 03) 2]+(3 \eta 21-\eta 03)(\eta 21+ \\
& \eta 03)[3(\eta 30+\eta 12) 2-(\eta 21-\eta 03) 2] \\
\varphi 6= & (\eta 20-\eta 02)[(\eta 30+\eta 12) 2-(\eta 21+ \\
& \eta 03) 2]+4 \eta 11(\eta 30+\eta 12)(\eta 21+\eta 03) \\
\varphi 7= & (3 \eta 21-\eta 30)(\eta 30+\eta 12)[(\eta 30+\eta 12) 2- \\
& 3(\eta 21+\eta 03) 2]+(3 \eta 12-\eta 30)(\eta 21- \\
& \eta 03)[3(\eta 30+\eta 12) 2-(\eta 21+\eta 03) 2]
\end{aligned}
$$

Pada ketujuh nilai invariant moments ini tidak berubah terhadap rotasi, translasi dan skala. (Hu, 1962)

\subsection{Akurasi Kemiripan Citra}

Dalam menentukan tingkat akurasi sistem image retrieval, tahapan yang dilakukan adalah menghitung normalisasi jarak dari kedua metode diatas kemudian pengukuran akurasi kemiripan dengan menggunakan rumus presicion sebagai berikut:

Akurasi $=$ ( jumlah data yang dianggap relevan oleh user / jumlah data yang diretrieval oleh sistem) x 100\%

\section{METODE PENELITIAN}

Penghitungan keakuratan tingkatkemiripan citra untuk penelusuran kembali sebuah citra beras pada penelitian ini adalah dengan melakukan pembandingan hasil dari nilai Manhattan distance pada color moments, invariant moment dan Statistical texture antara citra query dengan citra database. Pembandingan tersebut dilakukan untuk mengetahui tingkat kemiripan dari citra yang diuji dengan citra database. berikut:

Adapun langkah - langkahnya adalah sebagai

1. Melakukan input citra, baik citra database maupun citra query

2. Pre prosesing citra dengan Resizesing citra menjadi 300 x 300 pixel .

3. Penghitungan nilai fitur warna menggunakan Color Moments

4. Penghitungan nilai fitur brntuk menggunakan Invariant Moment

5. Menormalisasi nilai fitur bentuk dan warna

6. Membandingkan masing-masing nilai pada Color Moments dan Invariant Moment hasil normalisasi dari citra query dengan citra database

7. Melakukan klasifikasi bredasarkan fitur bentuk dan warna

8. Membuat rangking hasil pembandingan, semakin kecil selisihnya maka semakin memiliki kemiripan yang tinggi prosentase kemiripannya.

9. Menghitung akurasi similarity citra.

\section{HASIL DAN PEMBAHASAN}

Akuisisi citra yang digunakan sebagai bahan pengujian pada penelitian ini menggunakan citra dari beras dengan berbagai jenis melalui pengambilan gambar dengan menggunakan kamera dengan resolusi 12 mega pixel dan download citra beras dari internet. Citra obyek beras yang digunakan meliputi beberapa jenis beras yaitu: beras ketan merah, beras ketan hitam, beras ketan putih, beras rojolele, beras IR 64, beras menthik wangi, menir, beras original dan beras coklat dengan total citra adalah 90 citra beras. Masing-masing citra memiliki 10 citra dengan posisi pengambilan citra yang berbeda yaitu posisi depan, belakang, samping kiri, samping kanan dan posisi kemiringan $45^{\circ}$.

\subsection{Pre Processing Citra}

Sebagai pre processing dilakukan proses perubahan ukuran atau rezising untuk menghindari proses penghitungan yang lebih lama karena besarnya ukuran citra. Rezising adalah melakukan perubahan ukuran gambar yaitu menjadi 300 x 300 pixel . Sourcecodenya adalah sebagai berikut:

$$
\text { img_resizebr1=imresize(img_g1,[300,300]); }
$$

\subsection{Penghitungan Color Moment}

Bobot saturation lebih tinggi dari hue dan value saat kondisi citra database mengandung citra yang memiliki warna tidak beragam tapi 
dengan kedalaman warna yang berbeda-beda. Sedangkan Bobot hue lebih tinggi dari saturation dan value saat kondisi citra database mengandung intensitas warna yang beragam. Hasil uji penghitungan color moment pada citra beras seperti pada tabel 1 .

\begin{tabular}{lr|r}
\multicolumn{1}{c}{ Tabel 1 Nilai Color Moment citra uji Beras } \\
\hline $\begin{array}{c}\text { Nama } \\
\text { Citra }\end{array}$ & $\begin{array}{c}\text { nilai color } \\
\text { momen }\end{array}$ & \multicolumn{1}{c}{$\begin{array}{c}\text { distance } \\
\text { color }\end{array}$} \\
\hline citra uji & 0.10591 & \\
\hline B 1 & 0.08124 & 0.02467 \\
\hline B 2 & 0.15759 & 0.05168 \\
\hline B 3 & 1.33643 & 1.23052 \\
\hline B 4 & 1.33805 & 1.23214 \\
\hline B 5 & 0.14412 & 0.03821 \\
\hline B 6 & 0.16001 & 0.0541 \\
\hline B 7 & 0.1399 & 0.03399 \\
\hline B 8 & 0.10591 & 0 \\
\hline B 9 & 0.08429 & 0.02162 \\
\hline B 10 & 0.20662 & 0.10071 \\
\hline
\end{tabular}

Secara komputasi fitur warna, citra B8 mempunyai distance color 0 (nol). Hal ini membuktikan bahwa tingkat kemiripannya dalam hal distribusi warna adalah $100 \%$, sedangkan citra beras dengan nama B3 dan B4 mempunyai tingkat kemiripan yang agak jauh karena hampir mendekati nilai 2. Hal ini dikarenakan B3.jpg dan B4.jpg memiliki warna yang berbeda sedangkan citra B8.jpg secara real phisik memiliki warna dan kecerahan yang sama.

\subsection{Penghitungan Invariant Moment}

Tahapan selanjutnya adalah menghitung nilai invariant moment dengan menghitung tujuh nilai invariant moment. Dari nilai invariant moment dapat diketahui kemiripan bentuk citra dilihat dari semakin kecilnya nilai invariant moment, semakin kecil semakin tinggi tingkat kemiripanannya. Adapun tabel hasil contoh penghitungan invariant moment adalah seperti pada tabel 2 .

Tabel 2 Nilai Moment invariant citra uji

\begin{tabular}{l|c|r}
\hline \multicolumn{1}{c}{$\begin{array}{c}\text { Nama } \\
\text { Citra }\end{array}$} & $\begin{array}{c}\text { nilai momen } \\
\text { invariant } \\
\text { (M4) }\end{array}$ & $\begin{array}{c}\text { nilai momen } \\
\text { invariant } \\
\text { (M6) }\end{array}$ \\
\hline citra uji & 0.1506709 & 0.14406032 \\
\hline B 1 & 1.05301955 & 1.049187 \\
\hline B 2 & 0.92222058 & 0.65713745 \\
\hline B 3 & 0.79498076 & 0.53380865 \\
\hline B 4 & 2.30678952 & 1.37385046 \\
\hline B 5 & 2.80684864 & 2.94092083 \\
\hline B 6 & 0.19100703 & 0.15677254 \\
\hline
\end{tabular}

\begin{tabular}{l|l|l}
\hline B 7 & 14.8063178 & 26.8028648 \\
\hline B 8 & 0.02363947 & 0.00376677 \\
\hline B 9 & 2.15046114 & 1.61300548 \\
\hline B 10 & 0,00130512 & 0.14406032 \\
\hline
\end{tabular}

Pada Tabel 2 menunjukkan nilai invarinant moment untuk M4 dan M6, dari ketujuh nilai invariant moment hasil ekstraksi dari 90 citra beras menunjukkan bahwa nilai fitur bentuk untuk M4 dan M6 yang memiliki konsistensi tinggi dimana nilai M4 dan M6 memiliki selisih yang rendah dan stabil. Hal ini yang dipakai sebagai rujukan untuk penghitungan nilai jarak pada fitur bentuk.

\subsection{Penghitungan Akurasi Kemiripan \\ Kemiripan citra dapat dilihat dari nilai} color moment dan nilai invariant moment antara citra query dengan citra database. Kemudian kedua nilai tersebut dinormalisasi untuk menyamakan skala jarak sehingga tidak terjadi perbedaan range yang sangat tinggi yang akan berpengaruh terhadap identifikasi akurasi kemiripan citra. Hasil dari perhitungan tersebut kemudian dipakai sebagai dasar penghitungan akurasi presisi untuk me-retrieve images. Hasil penghitungan nilai jarak kemiripan menggunakan manhattan distance [10] dapat dilihat pada Tabel 3.

Tabel 3 Nilai jarak setelah dinormalisasi

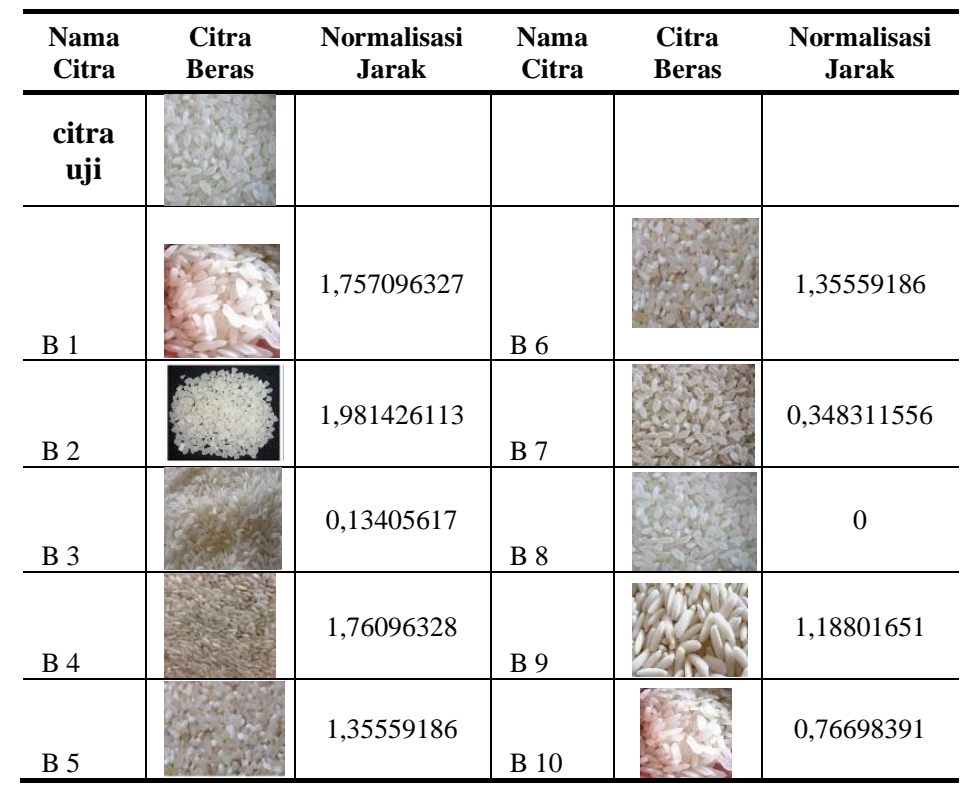

Pada Tabel 3 dapat dilihat kombinasi color moment dan invariant moment, sehingga terbukti penelusuran citra beras akan lebih akurat jika dilakukan kombinasi minimal 2 fitur. Hasil 
penghitungan setelah proses normalisasi jarak menunjukkan bahwa citra B8.jpg mempunyai akurasi kemiripan $100 \%$ karena nilai jaraknya adalah 0 (nol). Adapun tabel citra uji untuk citra beras dan normalisasi nilai jarak terdapat pada Tabel 4.

Tabel 4 Citra uji untuk beras

\begin{tabular}{l|c|c|c}
\hline $\begin{array}{c}\text { Nama } \\
\text { Citra }\end{array}$ & $\begin{array}{c}\text { Nilai } \\
\text { jarak } \\
\text { fitur } \\
\text { warna }\end{array}$ & $\begin{array}{c}\text { Nilai jarak } \\
\text { fitur bentuk }\end{array}$ & Normalisasi Jarak \\
\hline B 1 & 2.459354 & 4.198934 & 3.166025 \\
\hline B 2 & 2.491221 & 3.816156 & 2.532369 \\
\hline B 3 & 2.440545 & 3.719624 & 2.690894 \\
\hline B 4 & 2.454862 & 3.979763 & 2.378277 \\
\hline B 5 & 2.432262 & 4.390927 & 2.466569 \\
\hline B 6 & 2.464505 & 4.88668 & 2.901309 \\
\hline B 7 & 2.468381 & 3.021403 & 2.857243 \\
\hline B 8 & 0.000000 & 0.000000 & 0 \\
\hline B 9 & 2.419672 & 4.011734 & 2.785131 \\
\hline B 10 & 2.427297 & 4.404932 & 2.694156 \\
\hline
\end{tabular}

Tabel 5 Prosentase kemiripan dari citra B1, B2, B3 dan B4.

\begin{tabular}{l|c|c|c|c}
\hline \multicolumn{5}{c}{ Berdasarkan Nilai Manhattan Distance } \\
\cline { 2 - 5 } $\begin{array}{l}\text { Nama } \\
\text { Citra }\end{array}$ & $\begin{array}{l}\text { Awal } \\
(\%)\end{array}$ & $\begin{array}{l}\text { Rotasi } \\
\mathbf{9 0} \\
(\%)\end{array}$ & $\begin{array}{l}\text { Rotasi } \\
\mathbf{1 8 0}(\%)\end{array}$ & $\begin{array}{c}\text { Penskala- } \\
\text { an 2x(\%) }\end{array}$ \\
\hline & 82,35 & 83,66 & 84,55 & 82,35 \\
\hline & 84,22 & 85,25 & 80,35 & 80,20 \\
B 1 & 81,45 & 83,66 & 82,33 & 81,12 \\
\hline B 3 & 75,27 & 76,25 & 75,24 & 76,07 \\
\hline
\end{tabular}

Dari Tabel 5 dapat dilihat bahwa kemiripan ratarata dari data uji adalah lebih dari $80 \%$. Hal tersebut menunjukkan bahwa kombinasi dari color moment dan invarian moment untuk penelusuran kemiripan citra mempunyai tingkat akurasi yang tinggi.

\section{SIMPULAN}

Dari hasil pengujian dapat disimpulkan sebagai berikut:

1. Konsisten posisi pengambilan citra sangat berpengaruh terhadap tinggi rendahnya akurasi kemiripan antara citra query dengan citra database.

2. Pencahayaan pada proses pengambilan citra atau tingkat kecerahan (brightness), harus konsisten agar hasilnya akurat karena metode color moment merupakan metode yang menghasilkan vektor ciri dari sebaran warna yang sangat dipengaruhi oleh tingkat kecerahan citra.

3. Kombinasi dari metode color moment dan invariant moment menghasilkan tingkat akurasi kemiripan yang lebih tinggi dibandingkan tanpa melakukan kombinasi.

\section{REFERENSI}

[1] Agus, dkk, 2014, Penentuan Kualitas Beras Giling Menggunakan Analisis Citra, Jurnal Standardisasi, Vol 17 Nomor 1

[2] Acharya,T. dan Ray, A. K, 2005, Image Processing Principle and Applications, John Willey \& Sons, USA

[3] Ajay, dkk, 2013, Quality Evaluation of Rice Grains Using Morpological Methods, International Journal of Soft Computing and Engineering (IJCSE) Vol 2, ISSN: 2231-2307

[4] Anthony dkk, 1999, Non destructive Quantification of Internal Damage in Rough Rice Caused by Insect and Fungus, SPIE.Digital Library, Boston.

[5] Gonzales, R. C. dan Woods, R. E., 2008, Digital Image Processing ThirdEdition, Pearson Prentice Hall, New Jersey.

[6] Hemad, dkk, 2015, Potential Applications of Computer Vision in Quality Inspection of Rice

[7] Hiremath and Jagadesh, 2012, Content Based Image Retrieval Based on Color, Texture and Shape Feature Using Image and Its Complement, International Journal of Computer Science and Security, Volume (1) : Issue (4), India

[8] Hu M. K., Visual Pattern Recognition by Moment Invariants, IEEE Trans. Inf. Theory 12, 1962,179187

[9] Kementrian Pertanian RI. 2013. Konsumsi Rata-rata per Kapita Setahun Beberapa Bahan Makanan di Indonesia, 2009-2013. http://www.pertanian .go.id/Indikator/tabe-15b-konsumsi-rata.pdf, diakses 10 April 2015.

[10] Lingadalli, K.R. dan Ramesh, N., 2015, Content Based Image Retrieval Using Color, Shape and Texture, International Advanced Research Journal in Science, Engineering and Technology, ISSN (online) : 2393-8021 India. 